\title{
Effects of Lactitol-Oligosaccharides on Calcium and Magnesium Absorption in Rats
}

\author{
Shuichi Yanahira, Minoru Morita, Seiichiro AOE, ${ }^{1}$ \\ Toshiaki Suguri, Yukihiro TAKAdA, ${ }^{1}$ \\ Susumu MiURA, and Ichiro NAKAJIMA \\ Technology and Research Institute, and ${ }^{1}$ Nutritional Science Laboratory, \\ Snow Brand Milk Products Co. Ltd., Kawagoe 350-11, Japan
}

(Received September 25, 1996)

\begin{abstract}
Summary Lactitol-oligosaccharide (LO) was prepared from lactitol by transglycosylation reaction with Aspergillus oryzae $\beta$-galactosidase. LO is resistant to metabolism in the small intestine but not in the large intestine. The effects of LO, lactose (Lac), lactitol (Lacol) and galactooligosaccharide (GL) on calcium and magnesium absorption were determined by feeding 8-week-old Sprague-Dawley male rats diets containing $5 \%$ of the above carbohydrates for two weeks. The results obtained were as follows. 1) A significant increase of calcium absorption was observed in the LO diet. 2) A significant increase of magnesium absorption was observed in the LO, GL and Lacol diets. 3) The concentration of total volatile fatty acids (VFA) in the cecal contents increased significantly in the LO, GL and Lacol diets. The main constituent of VFA in the cecal contents was found to be acetic acid. 4) The correlations between calcium and magnesium absorption ratios and total VFA concentration in the cecum were found to be significantly related. These findings suggest that LO is metabolized to VFA, among which acetic acid concentration seems to have the most stimulatory effect on the absorption of calcium.

Key Words lactitol-oligosaccharide, lactitol, galactooligosaccharide, calcium, magnesium, absorption, volatile fatty acids, fermentable carbohydrate, cecum, rat
\end{abstract}

There are many studies on the effects of dietary factors on the stimulation of calcium absorption. These factors include lactose $(1,2)$, oligosaccharides $(3-8)$ and sugar alcohols $(9,10)$. These studies suggest that the volatile fatty acids (VFA) resulting from fermentation by the intestinal microflora would increase the soluble calcium and improve absorption ability in the epithelial of the intestine (11, 12). Goda et al. (13) reported that maltitol enhances the rate of transepithelial calcium transport in the lower part of the small intestine by modulating the passive diffusion of calcium. 
Recently, magnesium has become the subject of many studies along with calcium. This is due to the fact that although the average calcium intake of Japanese has increased, that of magnesium intake remains unchanged (14). Magnesium is an important constituent of bone and also acts as a cofactor of many enzymes (15). Recently, it has become well known that ischemic heart disease positively correlates to magnesium deficiency $(16,17)$. These facts suggest that it is important to carry out studies of the effects of dietary factors on the stimulation of magnesium absorption as well. It has been reported that fermentable carbohydrate intake stimulates magnesium absorption by lowering ileal $\mathrm{pH}$ and cecal $\mathrm{pH}$, thus increasing the concentration of soluble magnesium (3).

Lactitol-oligosaccharides (LO) are produced by Aspergillus oryzae $\beta$-galactosidase (18). These LO are not absorbed or hydrolyzed in the small intestine and reach the large intestine intact, where they are mainly metabolized into acetic acid and other VFA by the intestinal microflora, especially bifidobacteria (19).

In this study, we carried out a mineral balance study in order to investigate the effects of LO on mineral absorption in the large intestine, in relation to VFA concentrations in rat cecum.

\section{METHODS}

Preparation of oligosaccharides. The structures and composition of LO used for this study are summarized in Table 1. These oligosaccharides are prepared from

Table 1. Structures and composition of lactitol-oligosaccharides obtained from lactitol by Aspergillus oryzae $\beta$-galactosidase.

\begin{tabular}{|c|c|}
\hline Structures $^{1}$ & Composition (\%) \\
\hline$\beta$-D-Gal-( $(1 \rightarrow 4)-\beta$-D-Gal-( $1 \rightarrow 4)-\mathrm{D}-\mathrm{Glcol}$ & 3.5 \\
\hline 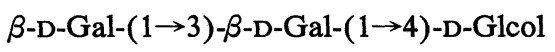 & 5.6 \\
\hline $\begin{array}{r}\beta-\mathrm{D}-\mathrm{Gal} \\
1 \\
\downarrow \\
5 \\
\beta \text {-D-Gal-(1 } \rightarrow 4)-\mathrm{D}-\mathrm{Glcol}\end{array}$ & 3.0 \\
\hline 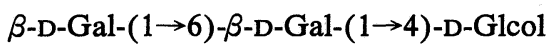 & 23.0 \\
\hline $\begin{array}{r}\beta \text {-D-Gal } \\
1 \\
\downarrow \\
6 \\
\beta \text {-D-Gal- }(1 \rightarrow 4)-\mathrm{D}-\mathrm{Glcol}\end{array}$ & 40.9 \\
\hline $\begin{array}{r}\beta \text {-D-Gal } \\
1 \\
\downarrow \\
1 \\
\beta \text {-D-Gal-(1 } \rightarrow 4)-D-G l c o l\end{array}$ & 24.0 \\
\hline
\end{tabular}

\footnotetext{
${ }^{1} \mathrm{Gal}$, galactose; Glcol, glucitol.
} 
lactitol by Aspergillus oryzae $\beta$-galactosidase according to a method reported previously (18). Galactooligosaccharide (GL) was prepared from lactose by a transglycosylation reaction catalyzed by Aspergillus oryzae $\beta$-galactosidase according to the method of Deya et al. (20). The GL was purified by charcoal column chromatography. The composition of GL is $75 \%$ trisaccharides, $20 \%$ tetrasaccharides and 5\% pentasaccharides, and the main structure is $\mathrm{Gal} \beta 1-6 \mathrm{Gal} \beta 1-4 \mathrm{Glc}$. Lactitol was kindly donated by Towa Chemical Ind. and lactose was purchased commercially.

Diets and animals. Table 2 shows the compositions of the experimental diets. All diets used in this study were based on the AIN-76 formulation. Each experimental diet contained 5\% lactose, 5\% galactooligosaccharide, 5\% lactitol and 5\% LO, respectively, replacing $\alpha$-corn starch in the control diet. Fifty-six male Sprague-Dawley rats (Charles River Inc.), with an initial mean weight of $300 \mathrm{~g}$, were housed in individual plastic metabolic cages in a temperature controlled $(22 \pm$ $2{ }^{\circ} \mathrm{C}$ ) room with $55 \pm 5 \%$ humidity and a $12 \mathrm{~h}$ light-dark cycle. After a 1-week period of adaptation to the control diet, the rats were randomly assigned to five diet groups with six rats in each group. They were fed the experimental diets described in Table 2 for two weeks, and diets and demineralized water were provided ad libitum. Body weight and food intake were recorded daily. For the calcium and magnesium balance study, fecal specimens were collected for three days during the first and second weeks after administration of the experimental diets. The feces was stored at $-20^{\circ} \mathrm{C}$ and dried by lyophilization. After a 2-week feeding period, the rats were fasted for $17 \mathrm{~h}$, anesthetized with diethyl ether and their cecums removed.

Analysis of calcium ( $\mathrm{Ca}$ ) and magnesium $(\mathrm{Mg})$. The amount of $\mathrm{Ca}$ and $\mathrm{Mg}$ in the experimental diets and feces were determined with an inductive coupled plasma emission spectrometer (ICP, LEEMAN LABS PS 100) after ashing at $550^{\circ} \mathrm{C}$. The ashed samples were dissolved in $6 \mathrm{~N}-\mathrm{HNO}_{3}$ and then placed on a hot plate to dry.

Table 2. Composition of experimental diets (\%).

\begin{tabular}{|c|c|c|c|c|c|}
\hline Constituent & Cont & Lac & GL & Lacol & LO \\
\hline Casein & 20.0 & 20.0 & 20.0 & 20.0 & 20.0 \\
\hline Corn starch & 65.2 & 60.2 & 60.2 & 60.2 & 60.2 \\
\hline Cellulose & 5.0 & 5.0 & 5.0 & 5.0 & 5.0 \\
\hline Corn oil & 5.0 & 5.0 & 5.0 & 5.0 & 5.0 \\
\hline $\mathrm{AIN}^{76}$ vitamin mixture ${ }^{1}$ & 1.0 & 1.0 & 1.0 & 1.0 & 1.0 \\
\hline AIN $^{76}$ mineral mixture ${ }^{1}$ & 3.5 & 3.5 & 3.5 & 3.5 & 3.5 \\
\hline DL-Methionine & 0.3 & 0.3 & 0.3 & 0.3 & 0.3 \\
\hline Lactose & - & 5.0 & - & - & 一 \\
\hline Galactooligosaccharide & - & - & 5.0 & - & - \\
\hline Lactitol & - & - & - & 5.0 & - \\
\hline Lactitololigosaccharide & - & - & - & - & 5.0 \\
\hline
\end{tabular}

Cont, control; Lac, lactose; GL, galactooligosaccharide; Lacol, lactitol; LO, lactitololigosaccharide. ${ }^{1}$ J. Nutr., 107, 1340-1348 (1977). 
The dried ashes were dissolved in $1 \mathrm{~N}-\mathrm{HNO}_{3}$. The apparent absorption ratios of $\mathrm{Ca}$ and $\mathrm{Mg}$ were determined by the following equation.

Apparent absorption ratio (\%)

$=[(\mathrm{Ca}$ or $\mathrm{Mg}$ intake $-\mathrm{Ca}$ or $\mathrm{Mg}$ feces excretion $) / \mathrm{Ca}$ or $\mathrm{Mg}$ intake $] \times 100$

Analysis of volatile fatty acids (VFA) and $p H$. The cecal contents $(1.0 \mathrm{~g})$ were homogenized in $9 \mathrm{ml}$ of water. The homogenate was centrifuged at $10,000 \times g$ for $20 \mathrm{~min}$ at $5^{\circ} \mathrm{C}$. Then, it was passed through a filter with a pore size $0.45 \mu \mathrm{m}$ (Millipore Japan Ltd., Japan), and VFA were analyzed using a carboxylic analyzer (Model S-14, Tokyo Rika, Japan).

The $\mathrm{pH}$ values of the cecal contents were determined with a flat glass electrode.

Statistical analysis. Group means were compared by one-way analysis of variance. Means were analyzed for significant differences $(p<0.05)$ by Tukey's multiple comparison test.

\section{RESULTS}

\section{Body weight and food intake}

The final body weight and food intake of the five groups were not significantly different (Table 3).

\section{Cecal weight and cecal contents weight}

The cecal weight and cecal contents weight were significantly elevated in the rats fed the LO, GL and Lacol diets (Table 4). Cecal enlargement in rats fed oligosaccharides has been reported previously $(6,12,19,21)$.

\section{Calcium and magnesium balance}

The results of the balance study of apparent $\mathrm{Ca}$ and $\mathrm{Mg}$ absorption ratios in the first and second weeks after administration of the experimental diets are shown in Table 5. The apparent absorption ratio of calcium increased significantly in the

Table 3. Effects of experimental diets on body weight gain, food intake and food efficiency.

\begin{tabular}{lccccc}
\hline Groups & $\begin{array}{c}\text { Initial weight } \\
(\mathrm{g})\end{array}$ & $\begin{array}{c}\text { Final weight } \\
(\mathrm{g})\end{array}$ & $\begin{array}{c}\text { Weight gain } \\
(\mathrm{g})\end{array}$ & $\begin{array}{c}\text { Food intake } \\
(\mathrm{g})\end{array}$ & $\begin{array}{c}\text { Food efficiency } \\
(\mathrm{g})\end{array}$ \\
\hline Cont & $300 \pm 5$ & $393 \pm 16$ & $93 \pm 16$ & $396 \pm 30$ & $23.5 \pm 3.3$ \\
Lac & $310 \pm 3$ & $391 \pm 20$ & $81 \pm 20$ & $403 \pm 33$ & $20.0 \pm 3.8$ \\
GL & $300 \pm 6$ & $366 \pm 17$ & $66 \pm 14$ & $363 \pm 36$ & $18.1 \pm 2.4$ \\
Lacol & $304 \pm 9$ & $370 \pm 30$ & $65 \pm 24$ & $362 \pm 41$ & $17.7 \pm 5.1$ \\
LO & $305 \pm 7$ & $383 \pm 22$ & $78 \pm 22$ & $369 \pm 14$ & $21.3 \pm 4.0$ \\
\hline
\end{tabular}

Cont, control; Lac, lactose; GL, galactooligosaccharide; Lacol, lactitol; LO, lactitololigosaccharide. Values are $\mathrm{M} \pm \mathrm{SD}(n=6)$. 
Table 4. Effects of experimental diets on carcass and cecal weight of rats.

\begin{tabular}{lccc}
\hline Groups & $\begin{array}{c}\text { Carcass weight } \\
(\mathrm{g})\end{array}$ & $\begin{array}{c}\text { Cecum weight } \\
(\mathrm{g})\end{array}$ & $\begin{array}{c}\text { Cecal contents weight } \\
(\mathrm{g})\end{array}$ \\
\hline Cont & $294 \pm 11.6$ & $2.3 \pm 0.5$ & $1.3 \pm 0.5$ \\
Lac & $297 \pm 12.8$ & $2.5 \pm 0.4$ & $1.5 \pm 0.4$ \\
GL & $272 \pm 9.0$ & $5.0 \pm 0.8^{\mathrm{a}, \mathrm{b}}$ & $4.2 \pm 0.5^{\mathrm{a}, \mathrm{b}}$ \\
Lacol & $279 \pm 22.6$ & $4.6 \pm 0.8^{\mathrm{a}, \mathrm{b}}$ & $3.4 \pm 0.6^{\mathrm{a}, \mathrm{b}}$ \\
LO & $287 \pm 16.1$ & $5.4 \pm 1.0^{\mathrm{a}, \mathrm{b}}$ & $4.3 \pm 0.7^{\mathrm{a}, \mathrm{b}}$ \\
\hline
\end{tabular}

Cont, control; Lac, lactose; GL, galactooligosaccharide; Lacol, lactitol; LO, lactitololigosaccharide. Values are $\mathrm{M} \pm \mathrm{SD}(n=6)$. ${ }^{\mathrm{a}}$ Significantly different from control group $(p<0.05)$. ${ }^{\mathrm{b}}$ Significantly different from lactose group $(p<0.05)$.

Table 5. Effects of experimental diets on apparent calcium and magnesium absorption.

\begin{tabular}{llllll}
\hline \multirow{2}{*}{ Groups } & \multicolumn{2}{c}{ Calcium (\%) } & & \multicolumn{2}{c}{ Magnesium (\%) } \\
\cline { 2 - 3 } \cline { 5 - 6 } & 1 week & 2 weeks & & 1 week & 2 weeks \\
\hline Cont & $33.5 \pm 2.9$ & $31.6 \pm 2.6$ & & $43.3 \pm 4.5$ & $41.6 \pm 4.7$ \\
Lac & $35.2 \pm 4.3$ & $34.3 \pm 3.0$ & & $59.2 \pm 3.8^{\mathrm{a}}$ & $52.7 \pm 6.0^{\mathrm{a}}$ \\
GL & $44.2 \pm 3.5^{\mathrm{a}, \mathrm{b}}$ & $40.7 \pm 3.9^{\mathrm{a}, \mathrm{b}}$ & & $73.7 \pm 0.5^{\mathrm{a}, \mathrm{b}}$ & $77.9 \pm 4.6^{\mathrm{a}, \mathrm{b}}$ \\
Lacol & $40.3 \pm 3.5^{\mathrm{a}, \mathrm{b}}$ & $37.8 \pm 3.2^{\mathrm{a}}$ & & $70.0 \pm 5.5^{\mathrm{a}, \mathrm{b}}$ & $72.6 \pm 5.0^{\mathrm{a}, \mathrm{b}}$ \\
LO & $48.4 \pm 3.8^{\mathrm{a}, \mathrm{b}, \mathrm{c}}$ & $47.2 \pm 4.7^{\mathrm{a}, \mathrm{b}, \mathrm{c}, \mathrm{d}}$ & & $75.1 \pm 3.1^{\mathrm{a}, \mathrm{b}}$ & $80.9 \pm 3.4^{\mathrm{a}, \mathrm{b}, \mathrm{c}}$ \\
\hline
\end{tabular}

Cont, control; Lac, lactose; GL, galactooligosaccharide; Lacol, lactitol; LO, lactitololigosaccharide. Values are $\mathrm{M} \pm \mathrm{SD}(n=6)$. ${ }^{\mathrm{a}}$ Significantly different from control group $(p<0.05)$. ${ }^{\mathrm{b}}$ Significantly different from lactose group $(p<0.05)$. ${ }^{\mathrm{C}} \mathrm{Sig}$ nificantly different from lactitol group $(p<0.05)$. ${ }^{\mathrm{d}}$ Significantly different from galactooligosaccharide group $(p<0.05)$.

rats fed the LO, GL and Lacol diets in the first week as compared to the rats fed the Cont and Lac diets. This became more notable for the rats fed the LO diets in the second week as compared to that of the rats fed other diets. The apparent absorption ratio of magnesium increased significantly in the rats fed the LO, GL and Lacol diets in the first and second weeks as compared to the rats fed the Cont and Lac diets.

pH and volatile fatty acids (VFA) in the cecal contents

Table 6 shows the pH and concentration of VFA in the cecal contents. Acetic acid and total VFA concentrations increased 2- to 3-fold in the rats fed the LO and GL diets as compared to those of the rats fed Cont and Lac diets. Acetic acid and total VFA concentrations also increased significantly in the rats fed Lacol diets as compared to those of the rats fed Cont and Lac diets. The cecal content $\mathrm{pH}$ decreased significantly in the rats fed the LO and GL diets. 
Table 6. Effects of experimental diets on cecal $\mathrm{pH}$ and volatile fatty acids (mg/ cecum).

\begin{tabular}{llcccc}
\hline Groups & $\mathrm{pH}$ & Acetic acid & Propionic acid & Butyric acid & Total VFA \\
\hline Cont & $7.4 \pm 0.3$ & $4.0 \pm 0.5$ & $1.5 \pm 0.3$ & $0.9 \pm 0.2$ & $6.5 \pm 0.7$ \\
Lac & $7.2 \pm 0.2$ & $5.3 \pm 0.5$ & $1.7 \pm 0.4$ & $1.1 \pm 0.3$ & $8.1 \pm 0.8$ \\
GL & $6.1 \pm 0.4^{\mathrm{a}, \mathrm{b}, \mathrm{c}}$ & $12.3 \pm 1.2^{\mathrm{a}, \mathrm{b}, \mathrm{c}}$ & $3.9 \pm 0.6^{\mathrm{a}, \mathrm{b}, \mathrm{c}}$ & $2.1 \pm 0.3^{\mathrm{a}, \mathrm{b}}$ & $18.3 \pm 1.5^{\mathrm{a}, \mathrm{b}, \mathrm{c}}$ \\
Lacol & $6.7 \pm 0.3^{\mathrm{a}, \mathrm{b}}$ & $7.4 \pm 0.9^{\mathrm{a}, \mathrm{b}}$ & $2.8 \pm 0.3^{\mathrm{a}, \mathrm{b}}$ & $2.0 \pm 0.5^{\mathrm{a}, \mathrm{b}}$ & $12.1 \pm 0.8^{\mathrm{a}, \mathrm{b}}$ \\
LO & $6.2 \pm 0.2^{\mathrm{a}, \mathrm{b}, \mathrm{c}}$ & $13.2 \pm 1.0^{\mathrm{a}, \mathrm{b}, \mathrm{c}}$ & $3.5 \pm 0.6^{\mathrm{a}, \mathrm{b}}$ & $2.5 \pm 0.7^{\mathrm{a}, \mathrm{b}}$ & $19.1 \pm 1.9^{\mathrm{a}, \mathrm{b}, \mathrm{c}}$
\end{tabular}

Cont, control; Lac, lactose; GL, galactooligosaccharide; Lacol, lactitol; LO, lactitololigosaccharide. Values are $\mathbf{M} \pm \mathbf{S D}(n=6)$. ${ }^{\text {a }}$ Significantly different from control group $(p<0.05)$. ${ }^{\mathrm{b}}$ Significantly different from lactose group $(p<0.05)$. ${ }^{\mathrm{c}}$ Significantly different from lactitol group $(p<0.05)$.
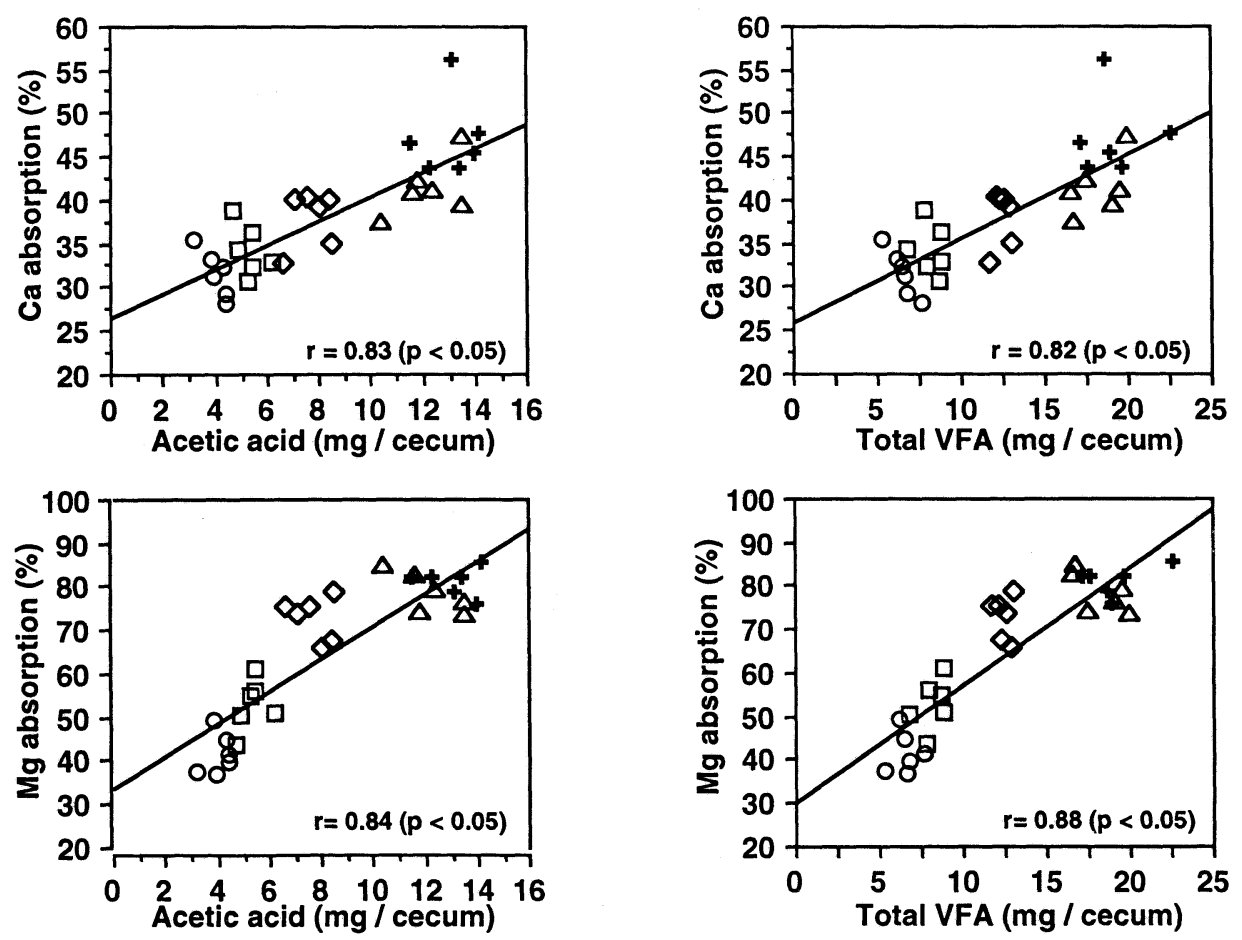

Fig. 1. Correlation between apparent $\mathrm{Ca}, \mathrm{Mg}$ absorption ratios and cecal acetic acid, total VFA concentrations. $\bigcirc$, control; $\square$, lactose; $\triangle$, galactooligosaccharide; $\diamond$, lactitol; + , lactitololigosaccharide.

\section{Cecal VFA and mineral absorption}

The correlations between the concentration of total VFA or acetic acid in the cecal contents and apparent mineral absorption ratio are shown in Fig. 1. The apparent absorption ratio of calcium was found to be related to the concentrations 
of total VFA and acetic acid in the cecal contents, with their correlation coefficients at 0.82 and $0.83(p<0.05)$, respectively. The correlation coefficients for propionic and butyric acids were 0.68 and 0.66 , respectively $(p<0.05$, data not shown). Positive correlation was also found between the apparent magnesium absorption ratio and total VFA and acetic acid concentrations. The correlation coefficients were 0.84 for acetic acid and 0.88 for VFA, which are higher than those values obtained for calcium. Also, positive correlations were found for propionic and butyric acids. Their correlation coefficients were 0.84 and 0.82 , respectively.

\section{DISCUSSION}

As shown in Table 2, the final body weight and food efficiency among the five groups were not significantly different, but those of the rats fed the GL and Lacol diets were slightly lower those of the rats fed other diets. Tokunaga et al. $(22,23)$ and Grenby and Phillips (24) reported that the administration of fructooligosaccharide and sugar alcohol to rats caused a significant decrease in the gastrointestinal transit time by bulking and osmotic effects, which could suppress the digestibility of nutrients. Our results may be explained in part by the above effects. However, such effects were not observed in rats fed the LO diet. It may be that the property of LO is different from that of GL and Lacol. Further study is needed to confirm this.

There are many reports on the stimulatory effects of fermentable carbohydrates on calcium absorption (4-8). These reports suggest that the lower $\mathrm{pH}$, as a result of carbohydrate fermentation in the large intestine, would increase the amount of soluble calcium. It is generally accepted that calcium must be in a soluble and ionized state to be absorbed in the intestine (25), and the lower $\mathrm{pH}$ thus leads to greater rates of calcium absorption. Moreover, it is known that sugar alcohol enhances the rate of transepithelial calcium transport in the lower part of small intestine by modulating the passive diffusion of calcium $(13,26)$.

Lactitol-oligosaccharides are not hydrolyzed by endogenous enzymes in the small intestine, and they reach the large intestine intact, where they are mainly metabolized into lactic, acetic, propionic and butyric acids by intestinal bacteria. We have observed a $\mathrm{pH}$ decrease in cecal contents due to an increase in the amount of fecal organic acids in rats (19). This study suggests that the stimulation of the calcium absorption by LO intake may induce an increase of cecal content weight $(27,28)$; a significant increase in cecal weight and decrease in $\mathrm{pH}$ of the cecal contents were observed in the rats fed LO, GL and Lacol, and the concentration of acetic acid and total VFA in the cecal contents were LO $>$ GL $>$ Lacol.

Subsequently, the correlations between the calcium absorption ratio and concentrations of total VFA and acetic acid in the cecums of rats fed these carbohydrates were analyzed statistically. The results suggest that the stimulation of calcium absorption in rats could be positively related to the concentration of total VFA in the cecum. Furthermore, it was suggested that acetic acid may play an important role in the stimulation of calcium absorption, since over $60 \%$ of the 
total VFA was found to be acetic acid.

Levrat et al. (12) reported that the stimulation of calcium absorption in rats fed inulin may be connected with propionic acid fermentation in the cecum. Ohta et al. (6) reported on lactate concentration in the cecum in relation to the stimulation of calcium absorption, as a result of fructooligosaccharide intake. The above studies mention several different kinds of organic acids, all of which have been found to stimulate calcium absorption. Different organic acids may have been produced due to the intake of different constituent monosaccharides in carbohydrates, thus resulting in the production and fermentation of different kinds of organic acids by intestinal bacteria.

It is known that LO and GL are selectively fermented by bifidobacterium, producing lactic and acetic acids in in vitro and in vivo tests (19). In this study, the VFA in the cecum of rats fed LO and GL were mainly acetic acid. This suggests that an increase of acetic acid production in the cecum could partially contribute to the stimulation of calcium absorption, but further study is needed to confirm this.

Furthermore, the concentrations of total VFA in the cecums of rats fed LO and GL diets were similar, but the apparent absorption ratio of calcium increased significantly in the rats fed the LO diets in the second week as compared to the rats fed the GL diets. This suggests that LO may have properties similar to maltitol (13, 26). Maltitol is known to enhance the rate of transepithelial calcium transport in the small intestine by modulating the passive diffusion of calcium. Calcium absorption is probably tightly controlled along the whole digestive tract, with less absorption of calcium in the upper half of the small intestine which is compensated by absorption in the lower half of the small intestine and large intestine $(12,29,30)$.

The apparent absorption ratio of magnesium was markedly improved in rats fed LO, GL and Lacol diets. Positive correlation between the apparent absorption ratio of magnesium and total VFA concentration in the cecum was similar to that observed for calcium absorption ratio. From these results, magnesium absorption may also be closely related to total VFA concentration in the cecum. Ohta et al. (6) reported a positive correlation between the L-lactate concentration in the cecum and the stimulation of magnesium absorption by fructooligosaccharides and other saccharides. Yoshida et al. (11) reported that the large intestinal bacteria have a stronger influence on magnesium absorption than on calcium absorption in gnotobiotic mice. It is generally assumed that magnesium absorption mainly takes place in the large intestine. Therefore, an increased supply of VFA may lead to greater magnesium absorption in the large intestine $(31,32)$. The physiological significance of this phenomenon is still uncertain, but the lowering of $\mathrm{pH}$ and increasing of VFA concentration in the large intestine may be an effective way to increase soluble magnesium (33).

In conclusion, the stimulatory effect of LO on calcium absorption may be the result of increased acetic acid concentration produced by intestinal bacteria fermentation, and the enhancement of the rate of transepithelial calcium transport in the small intestine by modulation of the passive diffusion of calcium. Furthermore, the 
stimulation of magnesium absorption by fermentable carbohydrates may be closely connected to the VFA concentration in the rat cecum.

\section{REFERENCES}

1) Sato, R., Noguchi, T., and Naito, H. (1983): Effect of lactose on calcium absorption from the rat small intestine with a non-flushed ligated loop. J. Nutr. Sci. Vitaminol., 29, 365-373.

2) Andrieux, C., Sacquet, E., and Gueguen, L. (1982): Microbial flora in the digestive tract and action of lactose on mineral metabolism. Reprod. Nutr. Dev., 22, 387-394.

3) Heijnen, A. M. P., Brink, E. J., Lemmens, A. G., and Beynen, A. C. (1993): Ileal pH and apparent absorption of magnesium in rats fed on diets containing either lactose or lactulose. Br. J. Nutr., 70, 747-756.

4) Brommage, R., Binacua, C., Antille, S., and Carrie, A. L. (1993): Intestinal calcium absorption in rat is stimulated by dietary lactulose and other resistant sugars. J. Nutr., 123, 2186-2194.

5) Shimura, S., Saeki, Y., Ito, Y., Suzuki, K., and Goto, S. (1991): Effects of galactooligosaccharides and fructooligosaccharides on mineral utilization in rats. J. Jpn. Soc. Nutr. Food Sci., 44, 287-291.

6) Ohta, A., Osakabe, N., Yamada, K., Saito, Y., and Hidaka, H. (1993): Effect of fructooligosaccharides and other saccharides on $\mathrm{Ca}, \mathrm{Mg}$ and $\mathrm{P}$ absorption in rats. $J$. Jpn. Soc. Nutr. Food Sci., 46, 123-129.

7) Claud, A., and Edomond, S. (1986): Effects of amylomaize starch on mineral metabolism in the adult rat; Role of the microflora. J. Nutr., 116, 991-998.

8) Chonan, O., and Watanuki, M. (1995): Effect of galactooligosaccharides on calcium absorption in rats. J. Nutr. Sci. Vitaminol., 41, 95-104.

9) Suzuki, K., Endo, Y., Uehara, M., Yamada, H., Goto, S., Imamura, M., and Shiozu, S. (1985): Effect of lactose, lactulose and sorbitol on mineral utilization and intestinal flora. J. Jpn. Soc. Nutr. Food Sci., 38, 39-42.

10) Ammann, P., Rizzoli, R., and Fleisch, H. (1988): Influence of the disaccharide lactitol on intestinal absorption and body retention of calcium in rats. J. Nutr., 118, 793-795.

11) Yoshida, T., Oowada, T., Ozaki, A., and Mizutani, T. (1993): Role of gastrointestinal microflora in the mineral absorption of young adult mice. Biosci. Biotech. Biochem., 57, 1775-1776.

12) Levrat, M. A., Rémésy, C., and Demigne, C. (1991): High propionic acid fermentations and mineral accumulation in the cecum of rats adapted to different levels of inulin. J. Nutr., 121, 1730-1737.

13) Goda, T., Takase, S., and Hosoya, N. (1993): Maltitol-induced increase of transepitherial transport of calcium in rat small intestine. J. Nutr. Sci. Vitaminol., 39, 589595.

14) Goto, S. (1986): Magnesium intake and its balance in Japanese. Jpn. J. Nutr., 44, 6167.

15) National Research Council, National Academy Press (1989): Recommended Dietary Allowances, 10th ed., pp. 187-194.

16) Chang, C., Varghese, J., Downey, J., and Bloom, S. (1985): Magnesium deficiency and myocardial infarct size in the dog. J. Am. Coll. Cardiol., 5, 280-289. 
17) Seeling, M. S. (1994): Consequences of magnesium deficiency on the enhancement of stress reactions; Preventive and therapeutic implications (A review). J. Am. Coll. Nutr., 13, 429-446.

18) Yanahira, S., Suguri, T., Yakabe, T., Ikeuchi, Y., Hanagata, G., and Deya, E. (1992): Formation of oligosaccharides from lactitol by Aspergillus oryzae $\beta$-galactosidase. Carbohydr. Res., 232, 151-159.

19) Yanahira, S., Morita, M., Aoe, S., Suguri, T., Nakajima, I., and Deya, E. (1995): Effects of lactitol-oligosaccharides on the intestinal microflora in rats. J. Nutr. Sci. Vitaminol., 41, 83-94.

20) Deya, E., Amaya, M., Nojiri, K., and Igarashi, S. (1982): Preparation of galactosyllactose by $\beta$-galactosidase. Rep. Res. Lab. Snow Brand Milk Prod. Co. Ltd., 78, 19-26.

21) Chonan, O., Matsumoto, K., and Watanuki, M. (1995): Effects of galactooligosaccharides on calcium absorption and preventing bone loss in ovariectomized rats. Biosci. Biotech. Biochem., 59, 236-239.

22) Tokunaga, T., Oku, T., and Hosoya, N. (1986): Influence of colonic intake of new sweetener fructooligosaccharide (Neosugar) on growth and gastrointestinal function of the rat. J. Nutr. Sci. Vitaminol., 32, 111-121.

23) Tokunaga, T., Oku, T., and Hosoya, N. (1989): Utilization and excretion of a sweetener, fructooligosaccharide (Neosugar), in rats. J. Nutr., 119, 553-559.

24) Grenby, T. H., and Phillips, A. (1989): Dental and metabolic effects on lactitol in the diet of laboratory rat. Br. J. Nutr., 61, 17-24.

25) Allen, L. H. (1982): Calcium bioavailability and absorption, A review. Am. J. Clin. Nutr., 35, 783-808.

26) Goda, T., Yamada, M., Takase, S., and Hosoya, N. (1992): Effect of maltitol intake on intestinal calcium absorption in the rat. J, Nutr. Sci. Vitaminol., 38, 277-286.

27) Passu, D., Chapuy, M. C., Milani, M., and Bellaton, C. (1976): Transepithelial calcium transport enhanced by xylose and glucose in the rat jejunal loop. Calcif. Tissue Res. (Suppl.), 21, 45-52.

28) Bronner, F. (1987): Intestinal calcium absorption; Mechanisms and applications. $J$. Nutr., 117, 1347-1382.

29) Petith, M. M., and Schedl, H. P. (1976): Intestinal adaptation to dietary calcium restriction; in vivo cecal and colonic calcium transport in the rat. Gastroenterology, 71, 1039-1042.

30) Demigne, C., Levrat, M. A., and Rémésy, C. (1989): Effects of feeding fermentable carbohydrates on the cecal concentration of mineral and their fluxes between the cecum and blood plasma in the rat. J. Nutr., 119, 1625-1630.

31) Behar, J. (1974): Magnesium absorption in the rat ileum and colon. Am. J. Physiol., 227, 334-340.

32) Rayssigueir, Y., and Rémésy, C. (1977): Magnesium absorption in the cecum of rats related to volatile fatty acid production. Am. Rech. Vét., 8, 105-110.

33) Schulz, A. G. M., Van Amelsvoort, J. M. M., and Beynen, A. C. (1993): Dietary native resistant starch but not retrograded resistant starch raises magnesium and calcium absorption in rats. J. Nutr., 123, 1724-1731. 